\title{
Mediterranean Gluten-Free Diet: Is It a Fair Bet for the Treatment of Gluten-Related Disorders?
}

\begin{abstract}
Karla A. Bascuñán ${ }^{1,2}$, Luca Elli ${ }^{1,3}$, Maurizio Vecchi ${ }^{3,4}$, Alice Scricciolo ${ }^{1}$, Federica Mascaretti ${ }^{1}$, Maria Parisi ${ }^{1}$, Luisa Doneda ${ }^{5}$, Vincenza Lombardo ${ }^{1}$, Magdalena Araya ${ }^{6}$ and Leda Roncoroni ${ }^{1,5 *}$
\end{abstract}

${ }^{1}$ Center for Prevention and Diagnosis of Celiac Disease, Gastroenterology and Endoscopy Unit, Fondazione Istituto di Ricovero a Carattere Scientifico (IRCCS) Ca' Granda Ospedale Maggiore Policlinico, Milan, Italy, ${ }^{2}$ Department of Nutrition, School of Medicine, University of Chile, Santiago, Chile, ${ }^{3}$ Department of Pathophysiology and Transplantation, University of Milan, Milan, Italy, ${ }^{4}$ General Surgery Unit, Fondazione Istituto di Ricovero a Carattere Scientifico (IRCCS) Ca' Granda Ospedale Maggiore Policlinico, Milan, Italy, ${ }^{5}$ Department of Biomedical, Surgical, and Dental Sciences, University of Milan, Milan, Italy, ${ }^{6}$ Institute of Nutrition and Food Technology, Instituto de Nutrición y Tecnología de los Alimentos (INTA), University of Chile, Santiago, Chile

Gluten-free diet (GFD) is the current treatment of gluten-related disorders. It eliminates wheat, barley, and rye, while the exclusion of oats is still under debate. GFD is based on a combination of naturally gluten-free foods and gluten-free substitutes of cereal-based foods. Although effective as treatment of gluten-related disorders, today there is concern about how to improve GFD's nutritional quality, to make it not only gluten-free, but also healthy. The "Mediterranean diet" (MedD) refers to the dietary pattern and eating habits typical of populations living in the Mediterranean basin, which have been associated with low prevalence of several diet-related pathologies. Here we present a narrative review of the current knowledge about GFD and MedD, their characteristics and central food components. Based on the Mediterranean diet pyramid developed by the Italian pediatric society, we propose a combination between the MedD and the GFD, an attractive alternative to reach a gluten-free state that at the same time is healthy, with a clear benefit to those who practice it.

Keywords: gluten-free diet, Mediterranean diet, food pyramid, cereals, pseudocereals

\section{INTRODUCTION}

Gluten related disorders share in common that they are triggered by gluten ingestion. They are a changing group of conditions, including celiac disease (CD), wheat allergy (WA), and nonceliac gluten sensitivity (NCGS) (1). Although mediated by different pathogenic pathways, their clinical manifestations may be similar (2), posing difficulties at the time of diagnosis (3). Their only effective treatment is a gluten-free diet (GFD), which eliminates wheat, rye, and barley consumption. GFD consists of a combination of naturally gluten-free foods (GFF) and gluten-free substitutes prepared with a variety of gluten-free foods and cereals (4). Although highly effective, GFD requires supervision by a trained professional, who must educate the patient and manage the diet, because this is often poor in fiber and vitamins and high in lipid and sugar content (5). In fact, excessive weight and obesity can also be a concern in celiac patients following a GFD, due to the rich-energy gluten- free foods/products commonly eaten (6). Currently available gluten-free products are often low in protein, with high fat and salt content. Higher levels of dietary fiber 
and lower sugar content have been recently reported (7). High consumption of rich-energy and rich-fat foods to compensate for dietary restriction has been reported in both adults and children with CD (8). There is concern today that the GFD may contribute to a microbiota signature (9) and cardiometabolic risk (obesity, dyslipidemia, insulin resistance, and metabolic syndrome) (8, $10,11)$. However, these risks are still not clear, a systematic review and meta-analysis concluded that $\mathrm{CD}$ was associated with a moderately increased cardiovascular risk (CVD), with limited evidence available (12).

The Mediterranean diet (MedD) is defined as the dietary pattern of people inhabiting the Mediterranean region. It is characterized by relatively high consumption of cereals, vegetables, legumes, fruits, nuts, fish, and olive oil, with moderate amounts of meat, milk and derivatives, sugars, and wine (13). This diet has proved successful in promoting health throughout life, contributing to the prevention of non-communicable chronic diseases (NCCD) (14). We therefore propose to analyze whether a MedD may be useful for those who must avoid gluten intake. We here review the MedD and GFD and, applying the concept of the food pyramid (15) used to teach the food groups that one should consume daily to remain healthy, we propose a gluten-free MedD pyramid.

\section{GLUTEN-FREE DIET}

Wheat has been essential to the diet since the first agricultural revolution in 10.000 BC. Gluten is contained in wheat, barley, and rye (16). Is a cohesive and visco-elastic material present in the alcohol-soluble fraction of gliadin and glutenins, widely consumed in customary Western diets $(17,18)$. The food industry extensively uses gluten due to its capacity to preserve the air in the protein matrices, improving the baking process, and enhancing properties of the processed foods $(19,20)$. Still, today GFD is also the treatment of patients with other gluten-related disorders, including NCGS and WA $(18,21)$. Replacing gluten-containing cereals is often technically challenging, and GFF often contain more lipids or more carbohydrate. Unless education and training are provided to the celiac patient, his/her choice will include a proportion of unhealthy foods, and additional health risks will be added (22).

\section{GLUTEN SUBSTITUTES IN GFD}

The only relevant change in GFD refers to the type of cereals to be included. This does not imply necessarily deterioration of the nutritional food value, because today, several cereals and pseudocereals do not contain gluten that can substitute wheat gluten (Table 1) (23).

\section{Gluten-Free Pseudocereals}

"Pseudocereals" is a non-botanical term that refers to dicotyledonous plants, while cereals refer to gramineae (Table 1). Pseudo-cereals are buckwheat, amaranth, quinoa, and chia. Chia (Salvia hispanica) originated in Mexico and Guatemala; Quinoa (Chenopodium quinoa Willd) and Amaranth (Amaranthus cruentus) are grown in South America and Buckwheat, originally
TABLE 1 | Nutritional characteristics of gluten-free alternative cereals.

\begin{tabular}{|c|c|}
\hline Cere & Nutritional characteristics \\
\hline $\begin{array}{l}\text { Pseudo-cereals } \\
\text { Buckwheat (Fagopyrum } \\
\text { esculentum)-Central } \\
\text { Asia }\end{array}$ & $\begin{array}{l}\text { - Source of antioxidants: carotenoids in quinoa } \\
\text { seeds, mainly represented by lutein, zeaxanthin, } \\
\text { and carotene (24); Chlorogenic acid, caffeic acid, } \\
\text { myricetin, quercetin, and kaempferol contained in } \\
\text { chia seeds (25); Polyphenols such as quercetin, } \\
\text { apigenin, and luteolin contained in buckwheat (26) }\end{array}$ \\
\hline $\begin{array}{l}\text { Amaranth (Amaranthus } \\
\text { cruentus)-South } \\
\text { America }\end{array}$ & $\begin{array}{l}\text { - The protein content of quinoa, amaranth, and } \\
\text { buckwheat, has been reported to be 12.0-18.9\% } \\
\text { and essential amino acids, particularly, cysteine } \\
\text { and methionine, are known to be higher than rice } \\
\text { and maize (27) } \\
\text { - High amount of dietary fiber (28) } \\
\text { - Quinoa has the highest fat content between } 2.0\end{array}$ \\
\hline $\begin{array}{l}\text { Quinoa (Chenopodium } \\
\text { quinoa Willd.)-South } \\
\text { America } \\
\text { Chia (Salvia } \\
\text { hispanica) - Central } \\
\text { America }\end{array}$ & $\begin{array}{l}\text { and } 9.5 \% \text {, rich in essential polyunsaturated fatty } \\
\text { acids such as linoleic and } \alpha \text {-linolenic (28) } \\
\text { - The presence of some "anti-nutritional factor" } \\
\text { reduces nutritional value, interfering on } \\
\text { digestibility, absorption, or utilization of nutrients. } \\
\text { The antinutritional factors in the quinoa seed are: } \\
\text { saponins, phytic acid, tannins, nitrates, oxalates, } \\
\text { and trypsin inhibitors (28) }\end{array}$ \\
\hline $\begin{array}{l}\text { Teff (Eragrostis } \\
\text { tef)-Ethiopia and Eritrea }\end{array}$ & $\begin{array}{l}\text { The flour is rich in fiber }(3.0 / 100 \mathrm{~g}) \\
\text { - The germ and bran are consumed along with } \\
\text { the endosperm } \\
\text { - A source of bioactive compounds such } \\
\text { as polyphenols } \\
\text { - Protein content is } 10.5-12.8 \% \\
\text { - Rich in minerals such as calcium, zinc, } \\
\text { magnesium, iron, phosphorous, and copper } \\
\text { - Contains good levels of vitamin C, niacin, vitamin } \\
\text { A, riboflavin, and thiamine }\end{array}$ \\
\hline $\begin{array}{l}\text { Sorghum [Sorghum } \\
\text { bicolor (L.) } \\
\text { Moench]-North-eastern } \\
\text { Africa }\end{array}$ & $\begin{array}{l}\text { - High presence of fibers } \\
\text { - Contains bioactive compounds: } \\
\text { proanthocyanidins, 3-deoxyanthocyanidins, } \\
\text { and flavones }\end{array}$ \\
\hline $\begin{array}{l}\text { Rice (Oryza sativa } \\
\text { L.)-Asia }\end{array}$ & $\begin{array}{l}\text { - The health benefits of whole grain derive mainly } \\
\text { from one of its major constituents, i.e., } \\
\text { the polyphenols }\end{array}$ \\
\hline $\begin{array}{l}\text { Maize (29) (Zea } \\
\text { mays)-Mexico }\end{array}$ & $\begin{array}{l}\text { - Provides many of the B complex vitamins, essential } \\
\text { minerals, and fiber } \\
\text { - Lacks vitamin } \mathrm{B}_{12} \text {, vitamin } \mathrm{C} \text {, and is a poor } \\
\text { source of calcium, folate, and iron }\end{array}$ \\
\hline $\begin{array}{l}\text { Oat (Avena } \\
\text { sativa)-England, France, } \\
\text { Poland, Germany, and } \\
\text { Russia }\end{array}$ & $\begin{array}{l}\text { - Starch is the major component } \\
\text { - High amounts of soluble food fiber in particular } \\
\text { beta-glucans (30) } \\
\text { - Grains contain natural antioxidants: tocols } \\
\text { (tocopherols and tocotrienols) and vitamin E (31) }\end{array}$ \\
\hline
\end{tabular}

from Central Asia, is now grown in Central and Eastern Europe (32). Pseudo-cereals are gluten-free and a suitable option to enhance the nutritional value of GFF. They are high in fiber, have good quality proteins, and unsaturated fatty acids (33). We briefly summarize their main characteristics in the next paragraphs.

\section{Antioxidants}

Pseudo-cereals are rich in antioxidants, mainly phenol functional groups, including flavonoids and phenolic acids, carotenoids, and tocols. They prevent oxidation and reactive oxygen species 
generation. Free radicals, generally in the form of reactive oxygen species, are by-products of cellular redox processes; in low concentrations, antioxidants have beneficial effects on cellular responses and immune function. Instead, at high levels, they cause oxidative stress by modifying cell structure and organelles. Today, it is generally agreed that oxidative stress plays a significant role in the development of chronic and degenerative diseases (34-38).

\section{Proteins}

Among pseudo-cereals, quinoa, amaranth, and buckwheat are non-conventional sources of good quality proteins. Although grown for thousands of years, they are not widely used due to their high price (39). Quinoa and buckwheat contain all essential amino acids and are also rich in sulfur amino acids and lysine, unlike other cereals, which are deficient in lysine (40).

\section{Carbohydrates and Dietary Fiber}

Quinoa has a high content of starch (41) that form semicrystalline structures referred to as "starch granules" (42) and a small percentage of sugars ( $\sim 3 \%$ refined sugar). All pseudo-cereals contain a high amount of dietary fiber, improve digestibility, and facilitates other nutrients absorption process in the large intestine (40). Besides, the consumption of dietary fiber is associated with higher post-meal satiety and decreased subsequent hunger (43).

\section{Lipids}

Quinoa has a significant lipid fraction, especially rich in essential polyunsaturated fatty acids. In recent decades, polyunsaturated fatty acids have gained importance because of their positive effects on CVD, prostaglandin metabolism, insulin sensitivity, the immune system, and cell membrane function (40). Chia is also an excellent source of mega-3 fatty acid (about 65\% of the oil content), especially $\alpha$-linolenic acid (43).

\section{Micro-Nutrients}

Quinoa is a good source of vitamin E, has high levels of thiamine, folic acid, and vitamin C. When compared to other cereals, quinoa is a good source of iron. However, its availability is limited by the presence of saponins and phytic acid. Amaranth and quinoa are good sources of calcium, iron, and magnesium; this is important because GFF are usually deficient in these minerals. Calcium, magnesium, and iron are the main mineral deficiencies in gluten-free products. Increasing calcium content is relevant for celiac patients because they frequently suffer osteopenia and osteoporosis (40). Chia biological value is better than that of other cereals, and also, its content of calcium, magnesium, and potassium is higher than in milk (43). Buckwheat is an excellent source of manganese, copper, magnesium, phosphorus, and vitamins (27).

Despite the known nutritional benefits of pseudo-cereals, several studies indicate that their use in GFF production is still scarce $(23,32,33,39,42,44,45)$. A Brazilian study analyzed the ingredients of GFF vs. their gluten-containing counterparts. It showed that sugar was the most frequent ingredient in both types of products' labels, along with salt and sodium. No GFF contained pseudo-cereals (24). The main ingredients were limited to rice, corn, soy, potato, and cassava. This latter is a perennial shrub of the Euphorbiaceae family, native to central South America, and currently cultivated in most tropical and sub-tropical areas of the American continent. It is valued for its roots rich in starches of high nutritional value (25). Do Nascimento et al. (24) analyzed the components used as substitutes of wheat flour in GFF in Brazil and found that these were mostly unfortified and refined $(26,46)$. This resulted in foods with low levels of B complex vitamins, iron, folate, and dietary fiber as compared with their gluten-containing counterparts. In Chile, a study that evaluated the "basic family basket" of GFF, described low protein content in comparison with the respective gluten-containing counterparts (47). Authors also found that while gluten-containing bread and cereals were mainly based on wheat, their corresponding GFF were based on rice, corn, cassava, and potato starch, all ingredients with low protein content and poorer nutritional quality $(28,48)$.

\section{Gluten-Free Cereals}

- Teff (Eragrostis tef) is an annual crop of the Poaceae (grass) family, native of Ethiopia and Eritrea. Teff grain is used as ingredient of foods and beverages because of its better nutritional properties in comparison with other grains, like wheat, barley, and maize. Teff's grain size is small and usually is eaten as wholegrain, therefore providing a good amount of fiber. It is also a good source of polyphenols. The comparative study of two teff varieties showed that their protein content was $10.5-12.8 \%$, which is higher than most other cereals $(49,50)$. It is also rich in minerals (calcium, zinc, magnesium, iron, phosphorous, and copper) and vitamins (C, A, niacin, riboflavin, and thiamine) (50).

- Sorghum [Sorghum bicolor (L.) Moench] originated in northeastern Africa. It contains high levels of fiber and bio-active compounds, including proanthocyanidins, 3deoxyanthocyanidins, and flavones. There is promising evidence showing that it inhibits cancer cell growth in vitro, and also, it has anti-inflammatory effects in animal models (51).

- Rice (Oryza sativa L.) is a GFF food consumed globally. While white rice is consumed worldwide, Asian populations also consume pigmented rice, known as black, purple, red, and brown rice. Black rice has a high concentration of tocopherols, oryzanols, polyphenols, B vitamins, and fiber. Black rice is particularly rich in anthocyanins, water-soluble flavonoids with antioxidant properties. Wholegrain rice is the unpolished version of grains containing the germ, bran, and endosperm. The health benefits of whole grain rice derive mainly from one of its polyphenols (52).

- Maize (Zea mays) is thought to be native of Mexico. It contains low amounts of calcium, folate, and non-heme iron. Fortification of maize flour and cornmeal with iron, other vitamins, and minerals is used to improve micronutrient intake and prevent iron deficiency in celiac patients (29).

- Oat (Avena sativa) originated in Europe and is now grown worldwide. Its primary component is starch $(60 \%$ of total dry weight), which digests slowly due to the presence of high 
amounts of fiber and oil that delays stomach emptying and favors digestion. As a result, a gradual supply of glucose, yielding low glycemic index, and prolonged satiety can be reached. Oat groats protein content is relatively high (15$20 \%$ by weight), and its digestibility (90\%) is better in comparison to rice and corn protein (30). Oat contains tocopherols, tocotrienols, and vitamin $\mathrm{E}$, which help reducing serum cholesterol and inhibit cell growth in certain cancers $(31,53)$, properties mainly attributed to the high content of oat-specific beta-glucans. Oat fibers increase the fecal bulk and have a positive effect on the intestinal microbiome. Less known bioactive components are the avenanthramides (phenolic amine conjugates); they have anti-inflammatory properties through the suppression of prostaglandin E2. Oats also suppresses vascular smooth muscle cell proliferation, a process known to be a contributing factor in the development of atherosclerosis (30). Yet, the effects of including oats in GFD are still unclear. Oats are most often contaminated with wheat, and therefore, the presence of gluten in oat-containing GFF must be assessed case by case (54-58). A Canadian Position study recommends consuming only those products included in the National Register of GFF of the Ministry of Health (59). Concern also rises from evidence suggesting that some oat varieties might have direct toxicity in CD. This is based in in-vitro studies that show that some oat varieties activate peripheral blood lymphocytes obtained from coeliac patients; the hypothesis is that the same phenomena could occur in duodenal mucosa of celiac persons, triggering glutendependent inflammation (60). At present, it is widely agreed that to introduce oats in GFD's patients, these must be in complete remission and receiving GFD (that excludes oats) for at least 6 months $(54-56,59)$.

\section{THE MEDITERRANEAN DIET AND ITS ORIGINS}

The MedD originated in the Mediterranean basin, where many populations in human history blended and developed. This region was a meeting place for people coming from different cultures, customs, languages, religions, eating habits (61). Over the centuries, the MedD incorporated foods from different cultures, like vineyards and olive trees (62). The discovery of America led to acquiring new culinary traditions and new food products, like tomatoes, peppers, chili peppers, corn, beans, and potatoes. Tomato was initially described as "exotic curiosities;" interestingly, they were the first red vegetable that enriched the Mediterranean food basket, subsequently becoming a symbol of the Mediterranean cuisine (61).

\section{Early Studies}

Since the mid-twentieth century, the available evidence showed that MedD diet protected against CVD and heart (CHD) diseases and was associated with lower all-cause mortality rates (63). In the early 1900s, De Langen noticed that Indonesian natives had lower serum cholesterol and lower risk of developing angina pectoris in comparison to Dutch people (63). In the 1950s, an epidemiologic study in Crete revealed that Cretans' diet contained more plant foods together with lower milk, meat, and fish consumption, compared to USA feeding patterns. Remarkably, meals were described to be "swimming" in olive oil and that this would "preserve the nutritive value of the food rather well" $(64,65)$. Later, Keys analyzed Italian data and observed that both blood cholesterol levels and frequency of heart attacks in the general local population were lower than in the more affluent groups. These and other studies contributed to the hypothesis that the prevalence, incidence, and mortality caused by CVD and CHD differ between different populations. Also, eating habits and other conditions can explain these differences, and that CVD and CHD episodes can be predicted based on individual (dietary) characteristics.

Today, the MedD does not only consist of a food consumption pattern, it also includes a pro-active lifestyle with regular physical exercise (62). MedD became part of the UNESCO Intangible Cultural Heritage list in 2010. Results of the 2003-2011 PREDIMED (Prevención con Dieta Mediterránea) study further reinforced the value of MedD for health promotion and proposed it as a model to follow globally (65).

The MedD has been inversely associated with several diseases, including some extensively investigated like CVD and cancer, alongside with associations with mental health, immunity, and quality of life (66). MedD has been described to change taxa enrichment in the intestinal microbiota, and adherence to the diet was positively associated with markers of lower frailty and improved cognitive functions in the elderly after 1-year intervention (67). Also, some of the microbiome changes were negatively associated with inflammatory markers, including C-reactive protein and interleukin-17. As stated by the authors, these findings suggest the possibility of modulating the gut microbiota by means of the diet, favoring healthy aging (67). A systematic review of five RCTs (68) on the effect of MedD in cognition and brain morphology and function showed that the data are mostly non-significant, however, the significant improvements in the cognitive domain compounds, in the more robust design study warrant further investigation (68). On the other hand, some reports suggest that adoption of the MedD could counteract the effects of several inflammatory components, decreasing the secretion of circulating and cellular biomarkers involved in the atherosclerotic process (69). The study of potential mechanisms that could explain such associations suggest that it is not only the nutrient dietary content, but the interaction and combination of foods, nutrients in food, non-nutritive substances, cooking techniques and lifestyle habits that make the MedD a potential tool to prevent and treat these situations (70). The scientific evidence that supports the practice of MedD for the prevention and treatment of a wide variety of conditions, reinforces the idea of promoting its use in patients who must follow restrictive diets, favoring and providing the basis for a healthier diet that can improve the quality of life of CD patients. 


\section{THE MEDITERRANEAN DIET, FUNCTIONAL FOODS, AND GRAINS}

Some foods such as phytochemicals, sulfur-containing compounds, carotenoids, monoterpenes, phytosterols, and different polyphenols. Today they classify as "nutraceuticals," the hybrid concept that mixes pharmaceuticals and nutrients $(71,72)$. Functional foods are those foods containing specific "nutraceuticals," which enhance health or reduce the chance of disease when regularly eaten. Vegetables are relevant components of the Mediterranean diet, rich in flavonoids and phytosterols. Fruits are good sources of terpenes, flavonoids, minerals, and vitamins, which protect against oxidative stress. Extra virgin olive oil has high concentrations of monosaturated fatty acid and phytochemicals. Recent studies show that olive oil plays a role in bone mineralization, reducing the risk of osteoporosis. Herbs, spices, onions, and garlic, which are widely used in the Mediterranean diet as condiments, contain flavonoids. Whole grains provide dietary fiber, antioxidants, resistant starch, phytoestrogens, and essential micro-nutrients. In the grain-refining process, most of the bran and some of the germ is removed, resulting in loss of dietary fiber and some vitamins, minerals, lignans, phytoestrogens, phenolic compounds, and phytic acid (Table 1).

In practical terms, MedD includes 3-5 daily servings of any of the following: wheat, corn, spelt, barley, sorghum, millet, buckwheat, quinoa, or rice. Whole grains can be consumed as wholemeal flour, used to produce bread, pasta, and other foods. A recent systematic review investigated the relationship between the intake of whole grains and CVD, concluding that there is a significant reduction of cardiovascular risk, stroke, CHD, type-2 diabetes, and obesity, for each $90 \mathrm{~g} /$ day (3 servings) increase of whole-grain intake $(73,74)$.

How foods are prepared is most relevant in MedD. When cooking tomatoes, for example, the addition of olive oil increases the absorption of lycopene carotenoids, improving

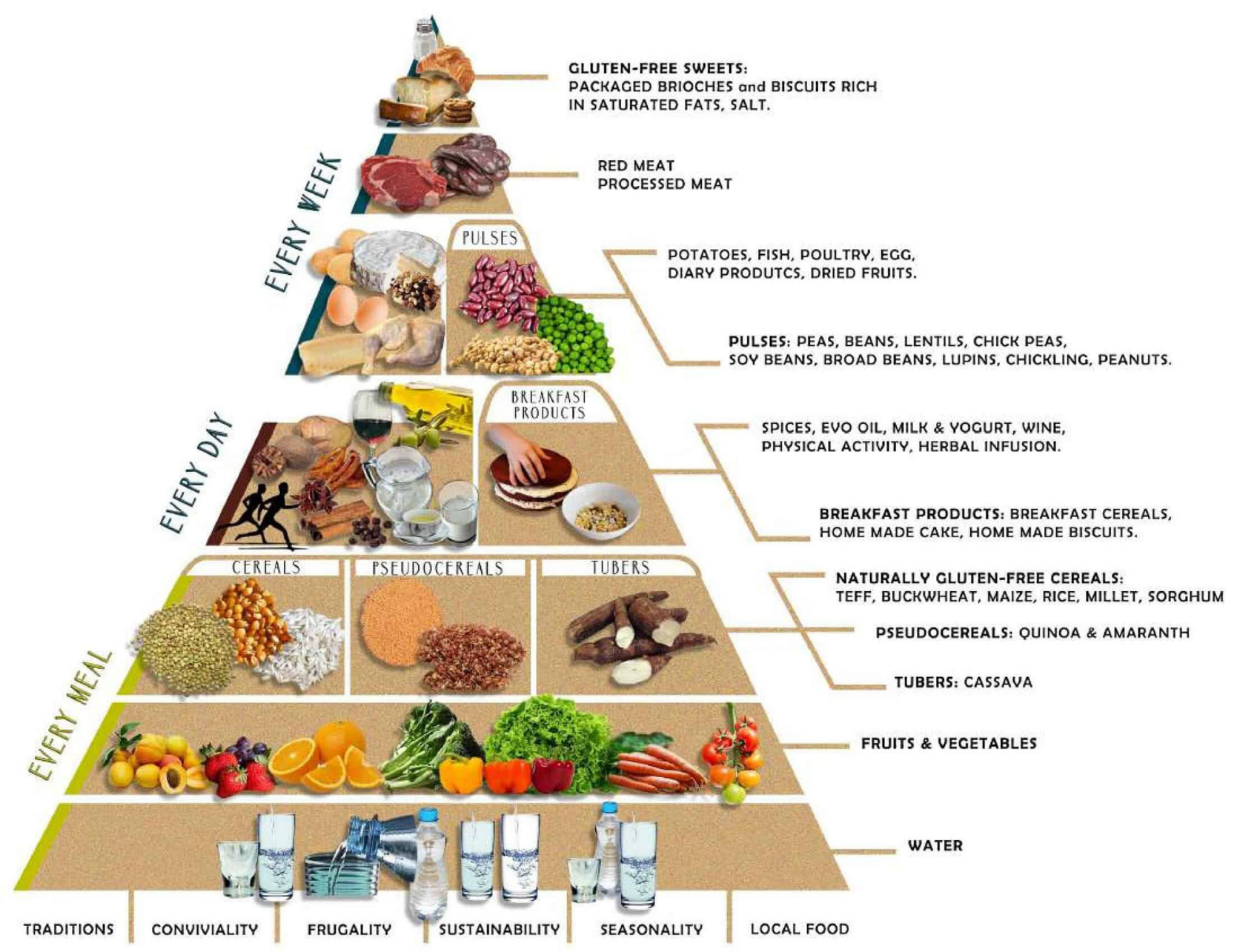

FIGURE 1 | The Mediterranean GFD pyramid: a gluten-free lifestyle. A new graphic representation of the food pyramid based on the MedD is conceived, where coexistence with the GFD is possible. The Mediterranean GFD pyramid gathers updated recommendations considering lifestyle, dietary, sociocultural, environmental, and health challenges of individuals who follow a GFD in the context of healthy eating based on the MedD. MedD, Mediterranean diet; GFD, gluten-free diet. 
its bio-availability and antioxidant effect. Another interesting concept is that it is not that a single nutrient yields a beneficial effect; it is the whole meal and dietary pattern that achieves the results described for the $\operatorname{MedD}(71,72)$.

The MedD is not just a food model but a mixture of art, science, habits, and traditions (including crops, harvesting, fishing, conservation, processing, and preparation of foods), all representing an integral part of the cultural heritage in the Mediterranean basin (75). It has incorporated lifestyle and cultural elements, which are located outside the pyramid. These include frugality, friendliness, traditions, sustainability, seasonality, and local foods. A recent addition is an adequate rest, which consists of a short nap during the day and at least $30 \mathrm{~min}$ daily physical exercise, both essential for a healthy lifestyle (76).

\section{THE GFD-MedD PYRAMID}

In 1992, the US Department of Agriculture developed nutritional recommendations for the population in the form of a pyramid, and shortly after, the MedD pyramid was designed as a way to emphasize the same concepts in the context of the Mediterranean dietary habits $(76,77)$. The Italian Pediatric Society later developed the "trans-cultural food pyramid" to teach healthy food choices to children. This latter pyramid provides the basic notions of a balanced diet, incorporating foods from Asian, African, and American cultures. Its use has now extended to adults and is becoming a relevant tool to improve MedD adherence in a multi-ethnic society. The trans-cultural pyramid includes buckwheat, amaranth, quinoa, and chia, all of them gluten-free and reasonable alternatives for celiac patients, who otherwise restrict their carbohydrate sources to rice, potatoes, and corn.

GFD and MedD can be integrated into a Mediterranean-GFD pyramid (Figure 1). On the basis, water, fruit, vegetables, and cereals have a major role. The pyramid offers a variety of glutenfree cereals, pseudo-cereals, and tubers (cassava). This lowest section shows foods that are consumed every day; homemade breakfast preparations should be preferred, which may add

\section{REFERENCES}

1. Catassi C, Bai JC, Bonaz B, Bouma G, Calabrò A, Carroccio A, et al. Nonceliac gluten sensitivity: the new frontier of gluten related disorders. Nutrients. (2013) 5:3839-53. doi: 10.3390/nu5103839

2. Bascuñán KA, Roncoroni L, Branchi F, Doneda L, Scricciolo A, Ferretti F, et al. The 5 Ws of a gluten challenge for gluten-related disorders. Nutr Rev. (2018) 76:79-87. doi: 10.1093/nutrit/nux068

3. Elli L, Branchi F, Tomba C, Villalta D, Norsa L, Ferretti F, et al. Diagnosis of gluten related disorders: celiac disease, wheat allergy and non-celiac gluten sensitivity. World J Gastroenterol. (2015) 21:7110-9. doi: 10.3748/wjg.v21.i23.7110

4. Pellegrini N, Agostoni C. Nutritional aspects of gluten-free products. J Sci Food Agric. (2015) 95:2380-5. doi: 10.1002/jsfa.7101

5. Vici G, Belli L, Biondi M, Polzonetti V. Gluten free diet and nutrient deficiencies: a review. Clin Nutr. (2016) 35:1236-41. doi: 10.1016/j.clnu.2016.05.002

6. Theethira TG, Dennis M. Celiac disease and the gluten-free diet: consequences and recommendations for improvement. Dig Dis. (2015) 33:175-82. doi: $10.1159 / 000369504$ spices, extra-virgin olive oil, milk, and yogurt, wine, and herbal infusions. After, are included those foods to be consumed weekly, like legumes, dried fruit, potatoes, and animal foods. In higher levels, red meat, and processed meat should be consumed less frequently, while white meats have less restriction. Gluten-free desserts should be only sporadically consumed and in small portions, because they are rich in simple sugars. Finally, it is worth considering that manufactured and naturally glutenfree products are not alike. The former tends to contain more saturated fats, sugar, and additives.

In summary, although large population studies are still lacking, this review provides robust arguments to propose the new GFD-MedD pyramid for those who must follow GFD, which will help making the diet not only gluten-free but also will make sure that it remains healthy. The Mediterranean-GFD Pyramid favors the use of raw materials and minimally processed GFF. Although wheat has a paramount position in the western diet it can be replaced by other cereals, some of which have improved nutritional characteristics.

\section{AUTHOR CONTRIBUTIONS}

$\mathrm{KB}, \mathrm{LE}, \mathrm{AS}, \mathrm{FM}, \mathrm{MP}$, and LR wrote the paragraphs on GFD and cereals. $\mathrm{LE}, \mathrm{MV}, \mathrm{VL}, \mathrm{LD}$, and $\mathrm{MA}$ wrote the paragraphs on origins of MedD and functional foods. KB, LE, and LR described grains properties and the new MedD pyramid. KB, LR, and MA supervised the manuscript. All authors approved the final version. All authors contributed to the article and approved the submitted version.

\section{FUNDING}

Research support for this study was provided by Fondazione IRCCS Ca' Granda and by grants from the Italian Ministry of Health and Lumbardy's Regional Government Authority (Ministero della Salute e Regione Lombardia call no. 2011-02348234).
7. Melini V, Melini F. Gluten-free diet: gaps and needs for a healthier diet. Nutrients. (2019) 11:170. doi: 10.3390/nu11010170

8. Anania C, Pacifico L, Olivero F, Perla FM, Chiesa C. Cardiometabolic risk factors in children with celiac disease on a gluten-free diet. World J Clin Pediatr. (2017) 6:143-8. doi: 10.5409/wjcp.v6.i3.143

9. Bascuñán KA, Araya M, Roncoroni L, Doneda L, Elli L. Dietary gluten as a conditioning factor of the gut microbiota in celiac disease. Adv Nutr. (2020) 11:160-74. doi: 10.1093/advances/nmz080

10. Emilsson L, Carlsson R, James S, Hambraeus K, Ludvigsson JF. Follow-up of ischaemic heart disease in patients with coeliac disease. Eur J Prev Cardiol. (2015) 22:83-90. doi: 10.1177/2047487313502446

11. Norsa L, Shamir R, Zevit N, Verduci E, Hartman C, Ghisleni D, et al. Cardiovascular disease risk factor profiles in children with celiac disease on gluten-free diets. World J Gastroenterol. (2013) 19:5658-64. doi: 10.3748 /wjg.v19.i34.5658

12. Emilsson L, Lebwohl B, Sundström J, Ludvigsson JF. Cardiovascular disease in patients with coeliac disease: a systematic review and meta-analysis. Dig liver Dis. (2015) 47:847-52. doi: 10.1016/j.dld.2015.06.004

13. Sofi F, Macchi C, Abbate R, Gensini GF, Casini A. Mediterranean diet and health status: an updated meta-analysis and a proposal for a 
literature-based adherence score. Public Health Nutr. (2013) 17:2769-82. doi: $10.1017 / S 1368980013003169$

14. Billingsley HE, Carbone S, Lavie CJ. Dietary fats and chronic noncommunicable diseases. Nutrients. (2018) 10:E1385. doi: 10.3390/nu10101385

15. Willett WC, Sacks F, Trichopoulou A, Drescher G, Ferro-Luzzi A, Helsing E, et al. Mediterranean diet pyramid: a cultural model for healthy eating. Am J Clin Nutr. (1995) 61:1402S-6S. doi: 10.1093/ajcn/61.6.1402S

16. Newberry C, McKnight L, Sarav M, Pickett-Blakely O. Going gluten free: the history and nutritional implications of today's most popular diet. Curr Gastroenterol Rep. (2017) 19:54. doi: 10.1007/s11894-017-0597-2

17. Lamacchia C, Camarca A, Picascia S, Di Luccia A, Gianfrani C. Cereal-based gluten-free food: how to reconcile nutritional and technological properties of wheat proteins with safety for celiac disease patients. Nutrients. (2014) 6:575-90. doi: 10.3390/nu6020575

18. Bascuñán KA, Vespa MC, Araya M. Celiac disease: understanding the glutenfree diet. Eur J Nutr. (2017) 56:449-59. doi: 10.1007/s00394-016-1238-5

19. Parada A, Araya M. History of gluten and its effects on celiac disease. Rev Med Chil. (2010) 138:1319-25. doi: 10.4067/S0034-98872010001100018

20. Elli L, Ferretti F, Orlando S, Vecchi M, Monguzzi E, Roncoroni L, et al. Management of celiac disease in daily clinical practice. Eur J Intern Med. (2019) 61:15-24. doi: 10.1016/j.ejim.2018.11.012

21. Elli L, Villalta D, Roncoroni L, Barisani D, Ferrero S, Pellegrini N, et al. Nomenclature and diagnosis of gluten-related disorders: a position statement by the Italian Association of Hospital Gastroenterologists and Endoscopists (AIGO). Dig Liver Dis. (2017) 49:138-46. doi: 10.1016/j.dld.2016.10.016

22. Rostami K, Bold J, Parr A, Johnson MW. Gluten-free diet indications, safety, quality, labels, and challenges. Nutrients. (2017) 9:E846. doi: $10.3390 /$ nu9080846

23. Saturni L, Ferretti G, Bacchetti T. The gluten-free diet: safety and nutritional quality. Nutrients. (2010) 2:16-34. doi: 10.3390/nu2010016

24. Do Nascimento AB, Fiates GMR, Dos Anjos A, Teixeira E. Analysis of ingredient lists of commercially available gluten-free and gluten-containing food products using the text mining technique. Int J Food Sci Nutr. (2013) 64:217-22. doi: 10.3109/09637486.2012.718744

25. Collar C, Conte P, Fadda C, Piga A. Gluten-free dough-making of specialty breads: significance of blended starches, flours and additives on dough behaviour. Food Sci Technol Int. (2015) 21:523-36. doi: $10.1177 / 1082013214552862$

26. Gallagher E, Gormley TR, Arendt EK. Recent advances in the formulation of gluten-free cereal-based products. Trends Food Sci Technol. (2004) 15:143-52. doi: 10.1016/j.tifs.2003.09.012

27. Dinu M, Macchia D, Pagliai G, Gori AM, Cesari F, Marcucci R, et al. Symptomatic efficacy of buckwheat products in non-celiac gluten sensitivity (NCGS). Asia Pac J Clin Nutr. (2017) 26:630-6. doi: 10.6133/apjen.072 016.07

28. Thompson T. Folate, iron, and dietary fiber contents of the gluten-free diet. $J$ Am Diet Assoc. (2000) 100:1389-96. doi: 10.1016/S0002-8223(00)00386-2

29. Ranum P, Peña-Rosas JP, Garcia-Casal MN. Global maize production, utilization, and consumption. Ann N Y Acad Sci. (2014) 1312:105-12. doi: $10.1111 /$ nyas. 12396

30. Gilissen L, van der Meer I, Smulders M. Why oats are safe and healthy for celiac disease patients. Med Sci. (2016) 4:21. doi: 10.3390/medsci4040021

31. Singh R, De S, Belkheir A. Avena sativa (Oat), a potential neutraceutical and therapeutic agent: an overview. Crit Rev Food Sci Nutr. (2013) 53:126-44. doi: 10.1080/10408398.2010.526725

32. Mota C, Santos M, Mauro R, Samman N, Matos AS, Torres D, et al. Protein content and amino acids profile of pseudocereals. Food Chem. (2016) 193:5561. doi: 10.1016/j.foodchem.2014.11.043

33. Alvarez-Jubete L, Arendt EK, Gallagher E. Nutritive value and chemical composition of pseudocereals as gluten-free ingredients. Int J Food Sci Nutr. (2009) 60:240-57. doi: 10.1080/09637480902950597

34. Taylor JRN, Belton PS, Beta T, Duodu KG. Increasing the utilisation of sorghum, millets and pseudocereals: developments in the science of their phenolic phytochemicals, biofortification and protein functionality. J Cereal Sci. (2014) 59:257-75. doi: 10.1016/j.jcs.2013.10.009

35. Hidalgo A, Ferraretto A, De Noni I, Bottani M, Cattaneo S, Galli S, et al. Bioactive compounds and antioxidant properties of pseudocereals-enriched water biscuits and their in vitro digestates. Food Chem. (2018) 240:799-807. doi: 10.1016/j.foodchem.2017.08.014

36. Monguzzi E, Marabini L, Elli L, Vaira V, Ferrero S, Ferretti F, et al. Gliadin effect on the oxidative balance and DNA damage: an in-vitro, ex-vivo study. Dig liver Dis. (2019) 51:47-54. doi: 10.1016/j.dld.2018.06.020

37. Moretti S, Mrakic-Sposta S, Roncoroni L, Vezzoli A, Dellanoce C, Monguzzi $\mathrm{E}$, et al. Oxidative stress as a biomarker for monitoring treated celiac disease. Clin Transl Gastroenterol. (2018) 9:157. doi: 10.1038/s41424-018-0031-6

38. Dolfini E, Elli L, Roncoroni L, Costa B, Colleoni M-P, Lorusso V, et al. Damaging effects of gliadin on three-dimensional cell culture model. World J Gastroenterol. (2005) 11:5973-7. doi: 10.3748/wjg.v11.i38.5973

39. Jacobsen SE, Sørensen M, Pedersen SM, Weiner J. Feeding the world: genetically modified crops versus agricultural biodiversity. Agron Sustain Dev. (2013) 33:651-62. doi: 10.1007/s13593-013-0138-9

40. Filho AMM, Pirozi MR, Borges JTDS, Pinheiro Sant'Ana HM, Chaves JBP, Coimbra JSDR. Quinoa: nutritional, functional, and antinutritional aspects. Crit Rev Food Sci Nutr. (2017) 57:1618-30. doi: 10.1080/10408398.2014.1001811

41. Tester RF, Karkalas J, Qi X. Starch-composition, fine structure and architecture. J Cereal Sci. (2004) 39:151-65. doi: 10.1016/j.jcs.2003.12.001

42. Steadman KJ, Burgoon MS, Lewis BA, Edwardson SE, Obendorf RL. Buckwheat seed milling fractions: description, macronutrient composition and dietary fibre. J Cereal Sci. (2001) 33:271-8. doi: 10.1006/jcrs.2001.0366

43. Ullah R, Nadeem M, Khalique A, Imran M, Mehmood S, Javid A, et al. Nutritional and therapeutic perspectives of Chia (Salvia hispanica L.): a review. J Food Sci Technol. (2016) 53:1750-8. doi: 10.1007/s13197-015-1967-0

44. Schoenlechner R, Siebenhandl S, Berghofer E. Pseudocereals. In: Gluten-Free Cereal Products and Beverages. Hardcover.

45. Janssen F, Pauly A, Rombouts I, Jansens KJA, Deleu LJ, Delcour JA. Proteins of amaranth (Amaranthus spp.), buckwheat (Fagopyrum spp.), and quinoa (Chenopodium spp.): a food science and technology perspective. Compr Rev Food Sci Food Saf. (2017) 16:39-58. doi: 10.1111/1541-4337.12240

46. Niewinski MM. Advances in celiac disease and gluten-free diet. J Am Diet Assoc. (2008) 108:661-72. doi: 10.1016/j.jada.2008.01.011

47. Estévez V, Ayala J, Vespa C, Araya M. The gluten-free basic food basket: a problem of availability, cost and nutritional composition. Eur J Clin Nutr. (2016) 70:1215-7. doi: 10.1038/ejcn.2016.139

48. Yazynina E, Johansson M, Jägerstad M, Jastrebova J. Low folate content in gluten-free cereal products and their main ingredients. Food Chem. (2008) 11:236-42. doi: 10.1016/j.foodchem.2008.03.055

49. Zhu F. Chemical composition and food uses of teff (Eragrostis tef). Food Chem. (2018) 39:402-15. doi: 10.1016/j.foodchem.2017.06.101

50. Gebremariam MM, Zarnkow M, Becker T. Teff (Eragrostis tef) as a raw material for malting, brewing and manufacturing of gluten-free foods and beverages: a review. J Food Sci Technol. (2014) 51:288-95. doi: 10.1007/s13197-012-0745-5

51. Simnadis TG, Tapsell LC, Beck EJ. Effect of sorghum consumption on health outcomes: a systematic review. Nutr Rev. (2016) 74:690-707. doi: 10.1093/nutrit/nuw036

52. Shao Y, Bao J. Polyphenols in whole rice grain: genetic diversity and health benefits. Food Chem. (2015) 180:86-97. doi: 10.1016/j.foodchem.2015.02.027

53. Regand A, Tosh SM, Wolever TMS, Wood PJ. Physicochemical properties of glucan in differently processed oat foods influence glycemie response. J Agric Food Chem. (2009) 57:8831-8. doi: 10.1021/jf901271v

54. Silano M, Penas Pozo E, Uberti F, Manferdelli S, Del Pinto T, Felli C, et al. Diversity of oat varieties in eliciting the early inflammatory events in celiac disease. Eur J Nutr. (2014) 53:1177-86. doi: 10.1007/s00394-013-0617-4

55. Maglio M, Mazzarella G, Barone MV, Gianfrani C, Pogna N, Gazza $\mathrm{L}$, et al. Immunogenicity of two oat varieties, in relation to their safety for celiac patients. Scand J Gastroenterol. (2011) 46:1194-205. doi: 10.3109/00365521.2011.603159

56. Comino I, Real A, De Lorenzo L, Cornell H, López-Casado MÁ, Barro F, et al. Diversity in oat potential immunogenicity: basis for the selection of oat varieties with no toxicity in coeliac disease. Gut J. (2011) 60:915-22. doi: $10.1136 /$ gut.2010.225268

57. Pinto-Sánchez MI, Causada-Calo N, Bercik P, Ford AC, Murray JA, Armstrong D, et al. Safety of adding oats to a gluten-free diet for patients with celiac disease: systematic review and meta-analysis of 
clinical and observational studies. Gastroenterology. (2017) 153:395-409. doi: 10.1053/j.gastro.2017.04.009

58. Aaltonen K, Laurikka P, Huhtala H, Mäki M, Kaukinen K, Kurppa K. The long-term consumption of oats in celiac disease patients is safe: a large cross-sectional study. Nutrients. (2017) 15:E611. doi: 10.3390/nu9060611

59. La Vieille S, Pulido OM, Abbott M, Koerner TB, Godefroy S. Celiac disease and gluten-free oats: a Canadian position based on a literature review. Can J Gastroenterol Hepatol. (2016) 2016:1870305. doi: 10.1155/2016/18 70305

60. Hardy MY, Tye-Din JA. T cells in coeliac disease: a rational target for diagnosis and therapy. Nat Rev Gastroenterol Hepatol. (2018) 15:583-4. doi: 10.1038/s41575-018-0043-4

61. Altomare R, Cacciabaudo F, Damiano G, Palumbo VD, Gioviale MC, Bellavia $\mathrm{M}$, et al. The mediterranean diet: a history of health. Heal Iran J Public Heal. (2013) 42:449-57.

62. Aboul-Enein BH, Puddy WC, Bernstein J. Ancel Benjamin Keys (1904-2004): his early works and the legacy of the modern Mediterranean diet. J Med Biogr. (2017) 1:967772017727696. doi: 10.1177/0967772017727696

63. Menotti A, Puddu PE. How the seven countries study contributed to the definition and development of the Mediterranean diet concept: a 50-year journey. Nutr Metab Cardiovasc Dis. (2015) 25:245-52. doi: 10.1016/j.numecd.2014.12.001

64. Nestle M. Mediterranean diets: historical and research overview. Am J Clin Nutr. (1995) 61:1313S-20S. doi: 10.1093/ajcn/61.6.1313S

65. Tracy SW. Something new under the sun? The Mediterranean diet and cardiovascular health. $N$ Engl J Med. (2013) 368:1274-6. doi: 10.1056/NEJMp1302616

66. Dinu M, Pagliai G, Casini A, Sofi F. Mediterranean diet and multiple health outcomes: an umbrella review of meta-analyses of observational studies and randomised trials. Eur J Clin Nutr. (2018) 72:30-43. doi: 10.1038/ejcn.2017.58

67. Ghosh TS, Rampelli S, Jeffery IB, Santoro A, Neto M, Capri M, et al. Mediterranean diet intervention alters the gut microbiome in older people reducing frailty and improving health status: the NU-AGE 1-year dietary intervention across five European countries. Gut. (2020) 69:1218-28. doi: 10.1136/gutjnl-2019-319654

68. Radd-Vagenas S, Duffy SL, Naismith SL, Brew BJ, Flood VM, Fiatarone Singh MA. Effect of the Mediterranean diet on cognition and brain morphology and function: a systematic review of randomized controlled trials. Am J Clin Nutr. (2018) 107:389-404. doi: 10.1093/ajcn/nqx070

69. Casas R, Sacanella E, Estruch R. The immune protective effect of the Mediterranean diet against chronic low-grade inflammatory diseases. Endocr Metab Immune Disord Drug Targets. (2014) 14:245-54. doi: $10.2174 / 1871530314666140922153350$
70. Serra-Majem L, Román-Viñas B, Sanchez-Villegas A, Guasch-Ferré M, Corella D, La Vecchia C. Benefits of the Mediterranean diet: epidemiological and molecular aspects. Mol Aspects Med. (2019) 67:1-55. doi: 10.1016/j.mam.2019.06.001

71. Ortega RM. Importance of functional foods in the Mediterranean diet. Public Heal Nutr. (2006) 9:1136-40. doi: 10.1017/S1368980007668530

72. Gul K, Singh AK, Jabeen R. Nutraceuticals and functional foods: the foods for the future world. Crit Rev Food Sci Nutr. (2016) 56:2617-27. doi: 10.1080/10408398.2014.903384

73. Kelly SAM, Hartley L, Loveman E, Colquitt JL, Jones HM, Al-Khudairy $\mathrm{L}$, et al. Whole grain cereals for the primary or secondary prevention of cardiovascular disease. Cochrane Database Syst Rev. (2017) 8:CD005051. doi: 10.1002/14651858.CD005051.pub3

74. Ferruzzi MG, Jonnalagadda SS, Liu S, Marquart L, McKeown N, Reicks $\mathrm{M}$, et al. Developing a standard definition of whole-grain foods for dietary recommendations: summary report of a multidisciplinary expert roundtable discussion. Adv Nutr. (2014) 5:164-76. doi: 10.3945/an.113.005223

75. Vitiello V, Germani A, Capuzzo Dolcetta E, Donini LM, del Balzo V. The new modern mediterranean diet italian pyramid. Ann Ig. (2016) 28:179-86. doi: 10.7416/ai.2016.2096

76. Bach-Faig A, Berry EM, Lairon D, Reguant J, Trichopoulou A, Dernini S, et al. Mediterranean diet pyramid today. Science and cultural updates. Public Heal Nutr. (2011) 14:2274-84. doi: 10.1017/S1368980011002515

77. D'Alessandro A, De Pergola G. Mediterranean diet pyramid: a proposal for italian people. Nutrients. (2014) 6:4302-16. doi: 10.3390/nu61 04302

Conflict of Interest: LE is a member of the Dr. Schaer Institute scientific board. LE and LR are inventors of a patented gluten challenge test for NCGS.

The remaining authors declare that the research was conducted in the absence of any commercial or financial relationships that could be construed as a potential conflict of interest.

The handling Editor declared a past co-authorship with one of the authors MV.

Copyright (๔ 2020 Bascuñán, Elli, Vecchi, Scricciolo, Mascaretti, Parisi, Doneda, Lombardo, Araya and Roncoroni. This is an open-access article distributed under the terms of the Creative Commons Attribution License (CC BY). The use, distribution or reproduction in other forums is permitted, provided the original author $(s)$ and the copyright owner(s) are credited and that the original publication in this journal is cited, in accordance with accepted academic practice. No use, distribution or reproduction is permitted which does not comply with these terms. 